\title{
The Heat Treatment Behavior of Super-High Strength Aluminum Alloys by Spray Forming
}

\author{
Guowei Zhang ${ }^{1,2}$, Zheng Chen ${ }^{1}$, Xiurong Zhu², Gang Chen ${ }^{2}$, Jing Zhai ${ }^{2}$, Anzhen Guo \\ Li Ma ${ }^{2}$, Wei Chen ${ }^{2}$, Haiying Xin ${ }^{2}$ \\ ${ }^{1}$ Northwesten Polytechnical University, School of Material Science and Technology, Xi'an, China \\ ${ }^{2}$ The Ningbo Branch of Ordnance Science Institute of China, Ningbo, China \\ Email: zhangguowei511@sina.com, howsoon@263.net
}

Received June 2013

\begin{abstract}
In order to understand the stress corrosion behavior of super-high strength aluminum alloys by spray forming, different aluminum alloys by different heat treatment was made. The results showed that the alloy with peak aging has the most sensitive stress corrosion cracking, the crack can even be seen using eyes; the alloys with two step aging were better than one step aging alloys, the alloys has not been found stress corrosion cracking.
\end{abstract}

Keywords: Super-High Aluminum Alloys; Spray Forming; Stress Corrosion Crack

\section{Introduction}

Aluminum alloys especially super-high aluminum alloys often restrict to use as structural materials because of stress corrosion cracking. But their properties can be improved by appropriate heat treatment such as two step aging and retrogression and reaging (RRA). And some other attempts such as composition modification and use new processing methods were made to further increase the properties of the alloys.

Spray forming as a promising method was used to manufacture high properties aluminum alloys such as 7000 series aluminum alloys. Spray forming processing, which combines the advantages of rapid solidification, homogeneous microstructure containing fine grains and avoiding the macro segregation, and high solute content, has already been applied to improve the properties of many alloys. Thus, it is possible to enhance the tensile strength values of the Al-Zn-Mg-Cu series alloys by spray forming technique. The addition of Mg, with low cost and low density, has been used together with Zn to form the phases of $\eta\left(\mathrm{MgZn}_{2}\right)$, which can enhance the strength [5-7]. Furthermore, the content of the $\mathrm{Zr}, \mathrm{Mn}, \mathrm{Ni}$ between $0.1 \%$ and $0.9 \%$ is acceptable for increasing mechanical properties [8]. However, the stress corrosion cracking properties limited the alloys to further application.

In this paper, the stress corrosion cracking properties of the alloys by spray forming were researched. And the microstructure and mechanical properties of the alloys were introduced.

\section{Experiment Procedures}

The nitrogen was used of the spray forming equipment as atomizer gas. The spray pressure was between $0.4-0.7$ $\mathrm{MPa}$, the atomizer scan frequency was between $20-25$ $\mathrm{Hz}$, the collector round frequency was between $3-5 \mathrm{~Hz}$ and the deposited distance was $650-750 \mathrm{~mm}$. The median frequency induction furnace was used as the melting furnace. The nominal chemical composition of the $\mathrm{Al}$ alloy was given in Table 1. The $\mathrm{N}_{2}$ gas was used as refiner and the spray temperature was $830^{\circ} \mathrm{C}-850^{\circ} \mathrm{C}$. Al$\mathrm{Cu}$ master, pure $\mathrm{Mg}$ and $\mathrm{Zn}$ were used in this experiment. Billets of spray forming were shown in Figure 1. The billets size were between $(\$ 220-\phi 280) *(300-350)$ mm. 2000 t reverse extruding machine was used to extrude the billets. Microstructure and mechanical properties of the alloy were investigated by S3400-N scanning electron microscopy and Instron Model 5585 respectively.

\section{Results and Discussion}

Table 2 was the tensile strength and elongations of the alloys by spray forming with different heat treatment. We can see that the tensile strength was $810 \mathrm{MPa}$ and the elongation was $4 \%$ of the alloy with peak aging. The tensile strength was $710 \mathrm{MPa}$ and the elongation was $8 \%$ of the alloy with two step aging. And the tensile strength was $800 \mathrm{MPa}$ and the elongation was $6 \%$ of the alloy with retrogression and reaging. Figure 2 was the microstructure of the alloys with different heat treatment. 
Table 1. The main chemical composition of tested alloy.

\begin{tabular}{lllllll}
\hline Elements & $\mathrm{Zn}$ & $\mathrm{Mg}$ & $\mathrm{Cu}$ & $\mathrm{Zr}$ & $\mathrm{Mn}, \mathrm{Ni}$ & $\mathrm{Al}$ \\
\hline Content(\%) & $11-13$ & $2.2-2.6$ & $1.0-1.3$ & $0.1-0.3$ & $0.2-0.6$ & $\mathrm{Bal}$.
\end{tabular}

Table 2. The mechanical properties of the alloys with different heat treatment.

\begin{tabular}{cccc}
\hline Heat treatment & Peak aging & Two step aging & RRA \\
\hline Rm/MPa & 810 & 710 & 800 \\
A/\% & 4 & 8 & 6 \\
\hline
\end{tabular}

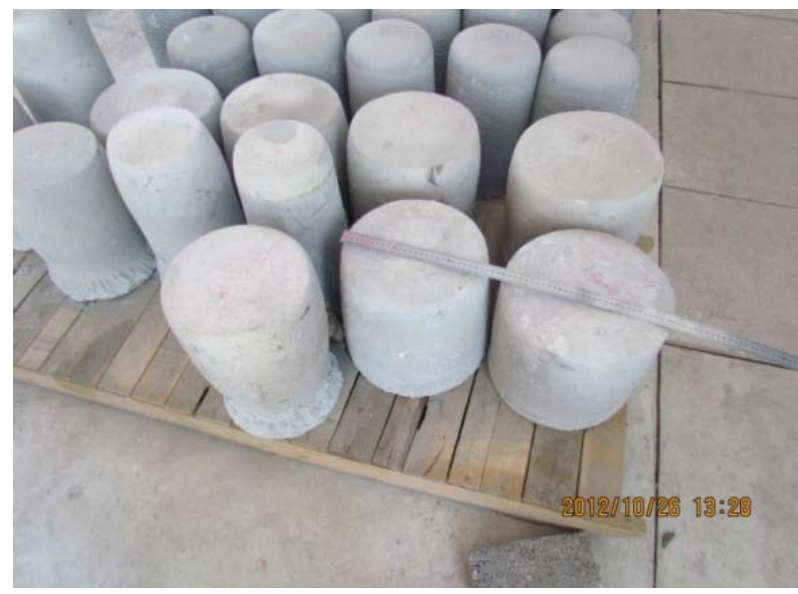

Figure 1. Billets of $\mathrm{Al}$ alloy by spray forming.

We can see that the main precipitate phases were G.P zones at peak aging and retrogression and reaging. While the main precipitate phases were $\operatorname{MgZn}_{2}$ at two step aging. The G.P zones are coherence with the matrix, so the strength of the alloys were enhanced in big extent, but the $\mathrm{MgZn}_{2}$ phases were coarsen and did not coherence with the matrix, so the tensile strength decreased in big extent.

The alloys were put at air condition for 12 months. And we found that the alloy with peak aging was cracked. Figure 3 was the crack of the alloy with peak aging.

From the photos we can see that the crack was intergranular, and the crack pattern like river. It's typical stress corrosion cracking. And the other two alloys didn't found crack even in scanning electron microscopy. So the peak aging heat treatment can not use for high strength aluminum alloys.

According to the theory of Mg-H composite, the interactional of $\mathrm{Mg}-\mathrm{H}$ lead to the increase of $\mathrm{H}$ concentration at grain boundary, the segregation of $\mathrm{H}$ at grain boundary would decrease the binding energy of grain boundary, so the crack would spread quicker. So the interaction of $\mathrm{Mg}-\mathrm{H}$ composite maybe the reason of stress corrosion cracking. In order to improve the stress corrosion cracking resistance of 7000 series alloys, appropriate heat

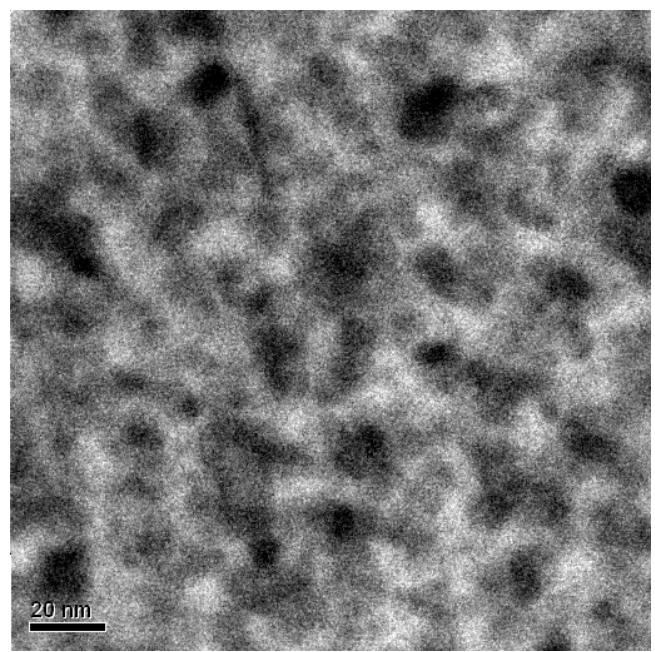

(a)

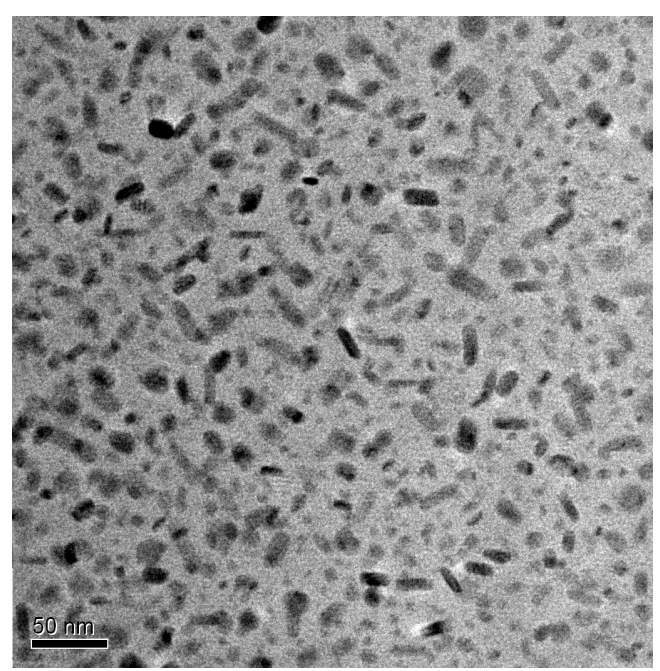

(b)

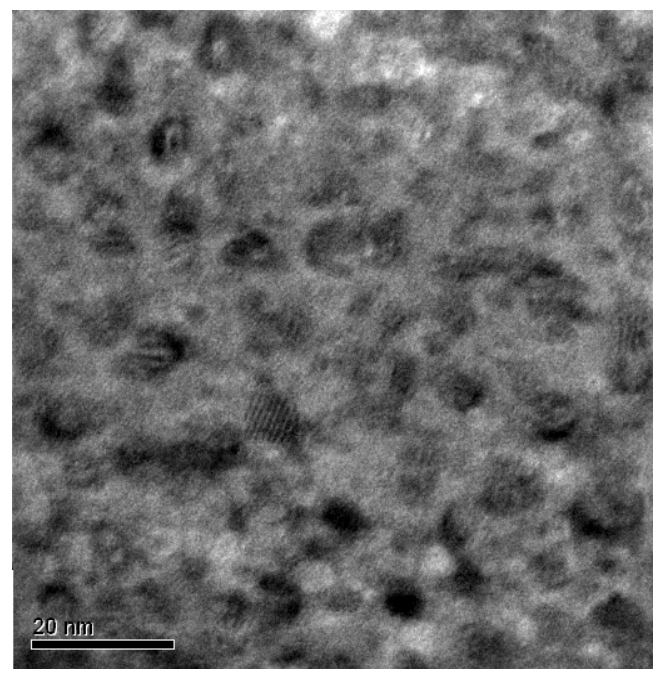

(c)

Figure 2. the microstructure of the alloys by spray forming with different heat treatment; (a) Peak aging; (b) Two step aging; (c) Retrogression and reaging. 


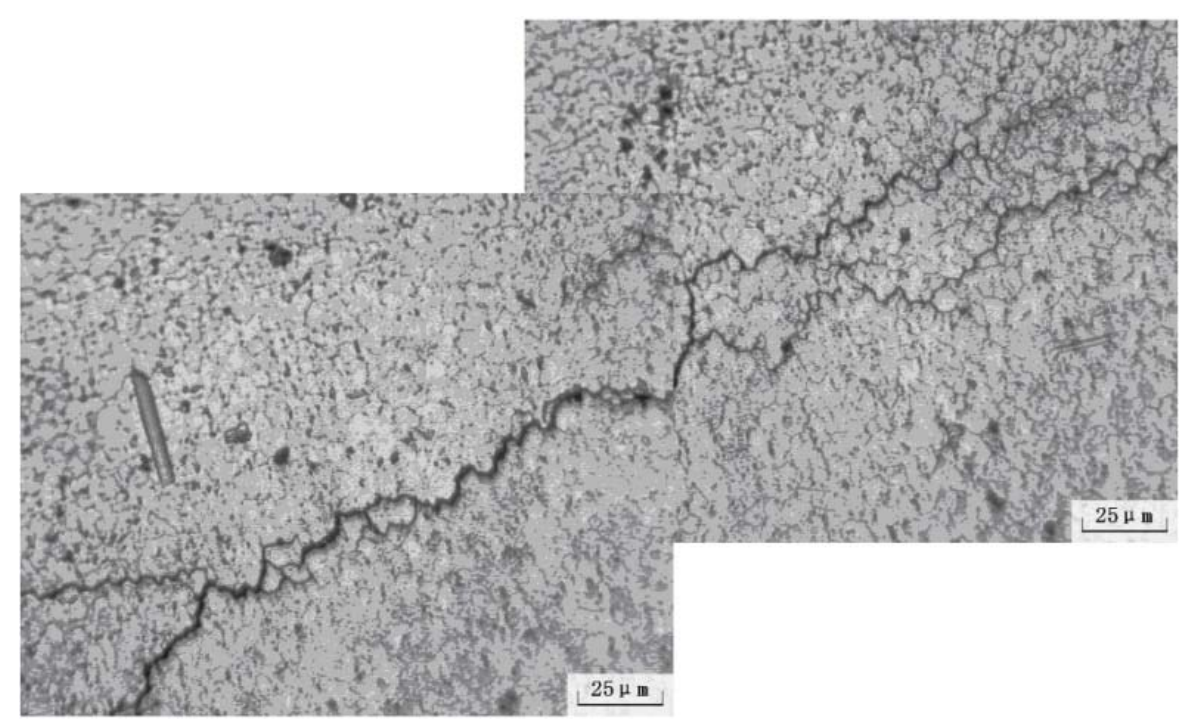

Figure 3. The crack of the alloy with peak aging.

treatment was needed to avoid the segregation of high concentration Mg. For example, two step aging which increases the second aging temperature can improve the stress corrosion cracking resistance of the alloy. That means the sensitivity of stress corrosion cracking was low at the second peak aging, this is because the concentration of $\mathrm{Mg}$ at the grain boundary was reduced with the second aging treatment. In addition, the precipitates phases in the alloy would change, that means $\alpha$ (supersaturation solid solution) $\rightarrow$ G. Pzone $\rightarrow \eta^{\prime}\left(\mathrm{MgZn}_{2}\right.$, metastable) $\rightarrow \eta\left(\mathrm{MgZn}_{2}\right)$. The fraction of $\eta^{\prime}\left(\mathrm{MgZn}_{2}\right)$ phases would increase all the time with the phases change going, so the free $\mathrm{Mg}$ in the grain would deplete, so the poor $\mathrm{Mg}$ zone would form. On the other side, the free $\mathrm{Mg}$ at the grain boundary would change little, so the rich-Mg formed. Because of the concentration difference, the free $\mathrm{Mg}$ at the grain boundary would diffuse to the inner of the grain by vacancies, so new $\eta^{\prime}\left(\mathrm{MgZn}_{2}\right)$ phases at the poor Mg zone would form, at last the free Mg at the grain boundary would decrease. At the same time, the $\eta^{\prime}$ $\left(\mathrm{MgZn}_{2}\right)$ phases would form at the grain boundary, so the free $\mathrm{Mg}$ at the grain boundary decreased further. So there's three results: 1) $\eta^{\prime}\left(\mathrm{MgZn}_{2}\right)$ phase was the trap of free $\mathrm{H}$, so the concentration of $\mathrm{H}$ at the grain boundary was reduced which improve the stress corrosion cracking resistance; 2) the stress of grain boundary fracture and the binding energy of grain boundary were increased because of the reduce of $\mathrm{Mg}$ segregation, so the Mg brittle at grain boundary was decreased; 3) because of the decrease of free $\mathrm{Mg}$, the interaction of $\mathrm{Mg}-\mathrm{H}$ was reduced, so the segregation of $\mathrm{H}$ at the grain boundary was reduced, so the hydrogen brittleness was reduced.

When the second aging temperature was increased, like two step aging and retrogression and reaging, the activation energy of the atom diffuse was decreased, so the hydrogen and $\mathrm{Mg}$ composite were interacting more intensity. So the stress corrosion cracking of the alloys were improved. So the two step aging and RRA technics would be used to use the high strength aluminum alloys.

\section{Conclusions}

1) The tensile strength and elongations were $810 \mathrm{MPa}$, 4\%; $710 \mathrm{MPa}, 8 \%$; $800 \mathrm{MPa}, 6 \%$ respectively at peak aging, two step aging and retrogression and reaging.

2) The main precipitate phases were G.P zones at peak aging and retrogression and reaging. While the main precipitate phases were $\mathrm{MgZn}_{2}$ at two step aging.

3) The alloy with peak aging was appeared stress corrosion cracking while the other two alloys did not appear stress corrosion cracking.

\section{REFERENCES}

[1] S. D. Liu, X. M. Zhang and M. A. Chen, "Effect of Zr Content on Quench Sensitivity of AlZnMgCu Alloys," Transactions of Nonferrous Metals Society of China, Vol. 17, 2007, pp. 787-792. http://dx.doi.org/10.1016/S1003-6326(07)60175-7

[2] C. Mondal, A. K. Mukhopadhyay, T. Raghu and V. K. Varma, "Tensile Properties of Peak Aged 7055 Aluminum Alloy Extrusions," Materials Science and Engineering: A, Vol. 455, No. 3, 2007, p. 673. http://dx.doi.org/10.1016/j.msea.2006.10.138

[3] M. Dixit, R. S. Mishra and K. K. Sankaran, "StructureProperty Correlations in Al 7050 and Al 7055 HighStrength Aluminum Alloys," Materials Science and Engineering: A, Vol. 478, No. 1-2, 2008, p. 163. http://dx.doi.org/10.1016/j.msea.2007.05.116

[4] Z. H. Li, B. Q. Xiong, Y. A. Zhang, et al., “Ageing Behavior of an Al-Zn-Mg-Cu Alloy Pre-Stretched Thick Plate,” Journal of University of Science and Technology 
Beijing, Vol. 14, No. 3, 2007, p. 246. http://dx.doi.org/10.1016/S1005-8850(07)60047-4

[5] K. H. Chen, H. W. Liu, Z. Zhang, et al., "The Improvement of Constituent Dissolution and Mechanical Properties of 7055 Aluminum Alloy by Stepped Heat Treatments," Journal of Materials Processing Technology, Vol. 142, No. 1, 2003, p. 190. http://dx.doi.org/10.1016/S0924-0136(03)00597-1

[6] R. C. Dorward and D. J. Beerntsen, "Grain Structure and Quench-Rate Effects on Strength and Toughness of AA7050 Al-Zn-Mg-Cu-Zr Alloy,” Metallurgical and Materials Transactions A, Vol. 26, 1995, pp. 2481-2484. http://dx.doi.org/10.1007/BF02671263

[7] M. Sharma, M. Amateau and T. Eden, "Mesoscopic Structure Control of Spray Formed High Strength Al-Zn-Mg-Cu Alloys,” Acta Materialia, Vol. 53, 2005, pp. 2919-2924. http://dx.doi.org/10.1016/j.actamat.2005.03.007

[8] M. Sharma, M. Amateau and T. Eden, "Hardening Mechanisms of Spray Formed Al-Zn-Mg-Cu Alloys with Scandium and Other Elemental Additions," Journal of Alloys and Compounds, Vol. 416, 2006, 135-142. http://dx.doi.org/10.1016/j.jallcom.2005.08.045

[9] R. Machler, P. Uggowitzer, C. Solenthaler, R. Pedrazzoli and M. Speidel, "Structure, Mechanical Properties, and Stress Corrosion Behavior of High Strength Spray Deposited 7000 Series Aluminum Alloy,” Materials Science and Technology, Vol. 7, 1991, pp. 447-451. http://dx.doi.org/10.1179/026708391790183880

[10] M. DeSanctis, "Structure and Properties of Rapidly Solidified Ultrahigh Strength Al-Zn-Mg-Cu Alloys Produced by Spray Deposition,” Materials Science and Engineering: A, Vol. 141, 1991, pp. 103-121. 